\title{
Information Markets and the Comovement of Asset Prices
}

\author{
Laura L. Veldkamp * \\ New York University \\ Stern School of Business
}

August 31, 2004

\begin{abstract}
Traditional asset pricing models predict that covariance between prices of different assets should be lower than what we observe in the data. This model generates high covariance within a rational expectations framework by introducing markets for information about asset payoffs. When information is costly, rational investors will not buy information about all assets; they will learn about a subset. Because information production has high fixed costs, competitive producers charge more for low-demand information than for high-demand information. A price that declines in quantity makes investors want to purchase a common subset of information. If investors price many assets using a common subset of information, then a shock to one signal is passed on as a common shock to many asset prices. These common shocks to asset prices generate 'excess covariance.' The cross-sectional and time-series properties of asset price covariance are consistent with this explanation.
\end{abstract}

*lveldkam@stern.nyu.edu, NYU Stern, Economics Department, 44 West 4th St., 7th floor, New York, NY 10012. Thanks to David Backus, Guido Lorenzoni, Thomas Sargent, Martin Schneider, Stijn Van Nieuwerburgh, Bernie Yeung, Gunter Strobl, and seminar participants at NYU, Rutgers, 2004 EFA meetings, Gerzensee summer symposium, and the 2004 SED meetings for helpful comments and conversations. Thanks also to Elif Sisli for her capable research assistance. JEL classification: D82, G14, G12. Keywords: Comovement, herding, information market, asset pricing. 
Asset pricing theory tells us that the price of an asset today should equal the expected present discounted value of the asset's payoffs. Standard stochastic discount factors have difficulty pricing assets, both over time and in the cross-section. An enormous amount of research has explored modifications of the standard stochastic discount factor with the goal of reconciling theory and data. Comparatively little attention has been paid to the expectations operator and the origin of the information sets that it rests on. This paper relaxes the assumption that investors have unlimited costless access to information and considers what kinds of information portfolios rational investors would hold. Exploring optimal information acquisition can yield important insights into cross-sectional asset pricing puzzles that arise in macroeconomics, international economics and finance. One of these is the comovement puzzle.

The high covariance of asset prices, relative to the covariance of their fundamentals, seems to defy rational explanation (Pindyck and Rotemberg, 1993; Barberis, Shleifer and Wurgler, 2002). Many take this 'excess covariance,' or comovement, to be evidence of investor irrationality. Zuckerman and Rao (2003) state,

If certain assets comove more than they should on the basis of their intrinsic value, such segmentation would indicate that the market is less sophisticated than imagined by the efficient markets hypothesis.

This paper offers an alternative explanation: Comovement is generated when investors purchase asset-payoff-relevant information from an information market. A profit-maximizing investor holding a portfolio of assets will typically not pay for information about every asset, because information is expensive. Instead, he will buy information about a subset of the assets and use this information to make inferences about the value of all the other assets. Using common information to price diverse assets induces the prices to covary, more than fundamentals would predict.

Consider the following example. Suppose the payoff to asset $A$ was equal to the sum of normally-distributed payoffs from two uncorrelated assets $B$ and $C$. If investors purchase information about the current-period payoff to $A$, but not information about $B$ and $C$, then when $A$ 's payoff rises, investors will attribute some of the increase to $B$ and some to $C$. 
Because they infer that the valuations of both assets rose, both prices will rise. If $A$ 's payoffs fall, the price of $B$ and $C$ will both fall. Prices of $B$ and $C$ will covary, even though investors know their payoffs are uncorrelated. The common source of information adds a new common shock in the prices of $B$ and $C$, which causes apparent excess covariance in their prices and their returns.

The question this raises is, why would investors all buy information about asset $A$ and not about assets $B$ or $C$ ? A noisy rational expectations model with a fixed cost for purchasing information (e.g. a multiple-signal version of Grossman and Stiglitz, 1980) would predict the opposite: investors should want signals that other investors are not purchasing. The signals that other investors see can be deduced, imperfectly, by observing asset prices. So, investors want different signals because they have more information content. With fixed-price information, the demand for a given signal is a strategic substitute.

Introducing markets for information creates a strategic complementarity that works through the market price for information. Information is a non-rival good with a high fixed cost of discovery and a low marginal cost of replication. Producing a small number of copies of a piece of information is very expensive, on a per-unit basis. Information that is mass-produced can be produced cheaply, and therefore sold at a low price. This is consistent with observed pricing schemes: A seminar for a small group of investors is expensive; a show on MSNBC is broadcast almost for free. This decreasing price in quantity generates the complementarity in information purchasing. Investors buy common information because the information that everyone is buying is cheap.

Not only do information markets coordinate information purchases, but the signals coordinated on are the signals most likely to produce comovement. In a competitive market for information, suppliers provide the highest-value signals. The highest value signals have the strongest predictive power for many other assets. Since it is these inferences about the value of other assets that causes comovement, the stronger the predictive power, the more comovement is generated.

Section 1 sets up a noisy rational expectations model with both the strategic substitutability and strategic complementarity in information acquisition. Section 2 shows that with fixed-cost information, investors' information is dispersed; one information shock affects 
a small fraction of investors' beliefs and generates a small amount of comovement. With information markets, information is concentrated on fewer signals; a shock to one signal can be a shock to the beliefs of a large number of investors and can move the prices of all the other assets in lock step. Numerical results show that common information shocks raise asset price correlations $40 \%$ above the correlation predicted by a model where investors observe all signals, and $30 \%$ above what a fixed-cost information model would predict. The first finding highlights the difficulty in matching comovement, using only portfolio rebalancing effects (as in Kodres and Pritsker 2002). Like liquidity (Calvo 1999) and wealth effects (Kyle and Xiong 2001), rebalancing is quantitatively significant in a crisis, when asset values change greatly, but generates only minor adjustments in response to normal daily fluctuations. The latter result highlights the importance of the endogenous information price.

By analyzing the determinants of information acquisition, the model can explain timeseries and cross-sectional properties of comovement. Section 3 builds a model where demand for information varies endogenously and shows that investors purchase more information about high-value asset markets. The abundant information reduces comovement. This is consistent with time-series evidence, showing that excess covariance is countercyclical and cross-sectional evidence, showing that excess covariance is stronger in emerging markets (Morck, Yeung and Yu, 2000). Veldkamp (2003) provides direct evidence that when a market's assets are valuable, information about those assets is abundant in the financial press. Since comovement arises when information is incomplete, what drives comovement changes is change in information flow. The difference between this mechanism and Ribeiro and Veronesi's (2002) is that they hold the information flow fixed and vary the uncertainty of priors over the business cycle. Finally, Campbell, Lettau, Malkiel and Xu (2001) show that between 1967-97, comovement decreased in the U.S.; Morck et. al. confirm this result in emerging markets. Adding a falling information cost to the model could generate these results.

Although the effects of information markets are explored in the context of an asset market, the results carry some general messages relevant to macro and international economics. One message is that the information agents choose to see can alter relationships between macro aggregates. The literature applying global games to monetary economics (Woodford 2002), 
business cycles (Angeletos and Pavan 2004, Lorenzoni 2004), and financial crises (Morris and Shin 1998), has made great inroads explaining observed responses to macroeconomic shocks, by adding private information. Analyzing information markets yields predictions about how public or private observed information will be, as well as which particular signals will be observed. Both the signal observed and the fraction of the population observing it are important determinants of aggregate covariance. A second message is that the extent of information frictions fluctuates with the value of the assets involved, be they financial assets, physical capital, or currency. The reason for this is that information has increasing returns in an asset's value; one signal can forecast the payoff of $\$ 1$ of asset value or $\$ 100$. As the value of an asset rises, so does the value of information about it. If agents choose how much information to acquire, then when asset values are low, information will be scarce and information frictions will be strong.

\section{Model}

The model is in the spirit of Grossman and Stiglitz (1980). It adds multiple assets with correlated payoffs and replaces Grossman and Stiglitz' constant information price with an endogenous price, set in an information market with increasing returns.

Preferences and Technology Time is discrete and continues forever. In each period $t$, a large finite number of two-period-lived, ex-ante identical agents are born. They have constant absolute risk aversion preferences over wealth $\left(W_{t+1}\right)$.

$$
U\left(W_{t+1}\right)=E_{t}\left[-e^{-a W_{t+1}}\right]
$$

There are two types of assets: one riskless asset with payoff $r>1$ and risky assets indexed by $m$ with payoff $u_{m t}$. Risky asset payoffs have a persistent component $\theta_{m t}$ and an idiosyncratic component $\epsilon_{m t} \sim i i d N\left(0, \sigma_{\epsilon}^{2}\right)$.

$$
u_{m t}=\theta_{m t}+\epsilon_{m t}
$$


The persistent component of payoffs is an $\operatorname{AR}(1)$ process with mean $\mu$ and shocks $\eta$.

$$
\theta_{m t}=(1-\rho) \mu_{m}+\rho \theta_{m(t-1)}+\eta_{m t}
$$

Innovations $\eta$ are jointly normally distributed: $\eta_{m t} \sim N(0, \Sigma)$, with covariances $E\left[\eta_{m} \eta_{n}\right]=$ $\sigma_{m n}$, and common variance $\sigma_{\eta t}^{2}$.

Information At the start of each period $t$, agent $i$ chooses whether or not to buy information about each asset. The information reveals the persistent component of next period's asset payoff $\left(\theta_{m t}\right)$. The asset payoff $u_{m t}$ and the state $\theta_{m t}$ are revealed publicly at the end of each period.

Asset Markets There are three risky assets. Risky asset $m$ has price $P_{m t}$; the riskless asset price is normalized to one. The per capita supply of the risky asset $x_{m t}$ is normally distributed: $x_{m t} \sim N\left(\bar{x}, \sigma_{x}^{2}\right)$. This supply is never observed. However, agents who know $\theta_{m t}$ can infer the value of $x_{m t}$ from the price. The role of the supply shocks is to prevent price from perfectly revealing $\theta_{m t}$ to uninformed agents.

Information Markets Three features of information markets are crucial. First, information is produced according to a fixed-cost technology. A signal $\theta_{m t}$ can be discovered at the beginning of period $t$ at a per-capita fixed cost $\chi$. This can be interpreted as the cost of hiring a journalist to interview people and find primary sources of information. The information, once discovered, can be distributed to other traders at zero marginal cost. Second, reselling purchased information is forbidden. The realistic counterpart to this assumption is intellectual property law that prohibits copying a publication and re-distributing it for profit. Third, there is free entry. Any agent can discover information at any time.

Information suppliers compete on price in a perfectly contestable market. ${ }^{1}$ Profits from information discovery depend on the price charged and demand for information, given the pricing strategies of other agents. One way to ensure that the market is contestable is to

\footnotetext{
${ }^{1}$ This market structure is used because it produces a simple pricing formula. Veldkamp (2003) shows that Cournot or monopolistically competitive markets produce similar results.
} 
force agents to choose prices in a first stage and choose entry in a second stage. This is a reasonable way to think of news markets where the price of the periodical is fixed well in advance and then editors decide whether or not to supply a story. By supplying the story, they would be entering the market for that piece of information.

Let $d_{i m t}=1$ if agent $i$ decides to discover information about market $m$ in period $t$ and $d_{i m t}=0$ otherwise. Let per capita demand for information with price $c_{i m t}$, given all other posted prices for the same information $c_{-i m t}$, be $I(\cdot, \cdot)$. Then the objective of the information producer is to maximize profit:

$$
\max _{d_{i m t}, c_{i m t}} d_{i m t}\left(c_{i m t} I\left(c_{i m t}, c_{-i m t}\right)-\chi\right)
$$

\section{Order of Events}

1. All agents enter the first period of life with wealth $W_{t}$, knowing the persistent component of the period $t$ asset payoff $\theta_{t}$ and $\sigma_{\eta t}$, the variance of $\theta_{t}$, conditional on $\theta_{t-1}$.

- Agents decide what price to set for information. Given all prices, they decide whether to discover information about each asset.

- Agents choose whether or not to purchase information about each asset $m$ that reveals $\theta_{m t}$.

- Informed and uninformed agents demand $D_{m}^{I}$ and $D_{m}^{U}$ units of the risky asset.

2. Payoffs are received. The asset supply $x_{m t}$ and the asset payoff $u_{m t}$, with its persistent and transitory components $\theta_{m t}$, and $\epsilon_{m t}$ are revealed.

3. In the second period of life, agents derive utility from terminal wealth $W_{t+1}$.

\section{Equilibrium}

Given an initial wealth, a persistent asset payoff process, payoff shocks, and risky asset supply, $\left\{\theta_{t}, \epsilon_{t}, x_{t}\right\}_{t=1}^{\infty}$, an equilibrium is a sequence of risky asset demands and a fraction of investors who purchase information $\left\{D_{i m t}, \lambda_{m t}\right\}_{t=1}^{\infty}$, and asset prices, information prices $\left\{P_{m t}, c_{m t}\right\}_{t=1}^{\infty}$, such that in every period $t>0$ 
1. Given prices $\left\{P_{m} t, c_{m} t\right\}$, agents choose whether to buy information about market $m$ $\left(I_{i m t}=1\right)$, or not $\left(I_{i m t}=0\right)$, and choose asset demands to maximize expected utility (1), subject to their budget constraint, ${ }^{2}$

$$
W_{t+1}=r W_{t}+\sum_{m=1}^{M}\left(D_{i m t} u_{m t}-r\left(P_{m t} D_{i m t}-I_{i m t} c_{j m t}\right)\right)+\pi_{i t}
$$

$\lambda_{t}$ is the fraction of agents who buy information. $\pi_{i t}$ is the profit agent $i$ makes from selling information.

2. Information supply and pricing strategies are a subgame perfect Nash equilibrium. They solve equation (2). If there are multiple Nash equilibria, information suppliers coordinate on the equilibrium that generates the highest total welfare for information purchasers. $^{3}$

3. The markets for risky assets and information clear.

\section{Information Provision and Price Covariance}

Rather than begin with the information and price dynamics produced by the full model, I begin by solving a series of simpler models that each highlight the role of one additional assumption in the model. Working with the simplified models also yields interpretable analytical results. Analyzing the full model requires numerical solution methods.

\subsection{Exogenous Information Supply}

A simple starting case is where all agents observe information about one asset $\left(\left[\lambda_{1}, \lambda_{2}, \lambda_{3}\right]=\right.$ $[1,0,0])$. Since endogenizing information supply with competitive information markets will

\footnotetext{
${ }^{2}$ Because of constant absolute risk aversion preferences, end-of-period information revelation, and the Markov state process, maximizing next period utility would also be optimal for an infinitely-lived agent.

${ }^{3}$ In a monopolistic competition model where information supply was not perfectly competitive and suppliers could earn some profit, this would be the highest-profit outcome. See Veldkamp (2004) for a analysis of such a model. In most cases, coordinating on other equilibria would affect which assets comove, but not the aggregate extent of comovement. Since the issue of multiple equilibria is a tangential one here, I choose to rule the possibility out, by assumption.
} 
cause agents to cluster their information demands, and this is the extreme form of clustering, it is a useful benchmark. ${ }^{4}$ Results will compare the covariance of asset prices in this model with two alternatives: covariance of prices in a model with full information $\left(\lambda_{m}=1 \forall m\right)$, and the covariance of prices in a model with no information $\left(\lambda_{m}=0 \forall m\right)$. The main result is that when the payoff covariance of two assets is sufficiently low, price covariance in this model will exceed both alternative measures of covariance.

When agents all have the same information set, the vector of prices takes the following form:

$$
P_{t}=\frac{1}{R}\left(E\left[\theta_{t}\right]-a \operatorname{Var}\left[u_{t}\right] x_{t}\right)
$$

where the expectation and variance-covariance matrix are conditional on the information set of the agents.

Full Information With full information, $\theta_{m t}$ is known for all assets $m$ and each asset's price can be written as

$$
P_{m t}^{F I}=\frac{1}{R}\left(\theta_{m t}-a x_{m t} \sigma_{\epsilon}^{2}\right)
$$

The covariance between the prices of assets 2 and 3 is

$$
\operatorname{cov}\left(P_{2}^{F I}, P_{3}^{F I}\right)=\frac{\sigma_{23}}{R^{2}\left(1-\rho^{2}\right)}
$$

The $\sigma_{23} /\left(1-\rho^{2}\right)$ term appears because $\sigma_{23}$ is the covariance of innovations to an $\operatorname{AR}(1)$ process $\theta$ with persistence $\rho$. The covariance of the $\operatorname{AR}(1)$ process is $1 /\left(1-\rho^{2}\right)$ times the covariance of its innovations.

No Information With no information, all knowledge about $\theta_{t}$ is based on its $(t-1)$ realization.

$$
P_{t}^{N I}=\frac{1}{R}\left((1-\rho) \mu+\rho \theta_{(t-1)}-a\left(\Sigma+\sigma_{\epsilon}^{2} I\right) x\right)
$$

\footnotetext{
${ }^{4}$ Ribeiro and Veronesi (2002) employ a similar information structure.
} 
The covariance between the prices of assets 2 and 3 is

$$
\operatorname{cov}\left(P_{2}^{N I}, P_{3}^{N I}\right)=\frac{\rho^{2} \sigma_{23}}{R^{2}\left(1-\rho^{2}\right)}+\frac{a^{2} \sigma_{x}^{2}}{R^{2}}\left(\sigma_{12} \sigma_{13}+2 \sigma_{23}\left(\sigma_{\eta}^{2}+\sigma_{\epsilon}^{2}\right)\right)
$$

The first term is what price covariance would be if agents did not adjust their portfolios over time. It is just the covariance of $\frac{1}{R} \hat{\theta}_{2}$ and $\frac{1}{R} \hat{\theta}_{3}$. The second term arises from agents who try to manage risk by adjusting their portfolios when prices change.

Information About One Asset When agents all observe $\theta_{1 t}$, the price of asset 1 is the full information price $p_{1 t}^{F I}$. The prices of assets 2 and 3 change. Let $\hat{\theta}_{m t}$ denote the $(t-1)$ expectation $(1-\rho) \mu+\rho \theta_{m(t-1)}$. For assets $m \in\{2,3\}$, the expected value of $\theta_{m}$ conditional on observing $\theta_{1}$ is

$$
E\left[\theta_{m t} \mid \theta_{1 t}\right]=\hat{\theta}_{m t}+\frac{\sigma_{1 m}}{\sigma_{\eta}^{2}}\left(\theta_{1 t}-\hat{\theta}_{1 t}\right)
$$

The price and the payoffs of the asset that investors learn about will always have the same covariance with all other assets. This is because the optimal inference weights the innovation to $\theta_{1}$ by its covariance with asset $m$. An optimal linear forecast always matches this moment. When investors learn about asset 1, there will be no 'excess comovement' between assets 1 and 2, or assets 1 and 3. The interesting comparison will be across the covariances of asset prices 2 and 3 that result from each information regime.

The vector of prices will be

$$
P_{t}=\frac{1}{R}\left(E\left[\theta_{t} \mid \theta_{1 t}\right]-a V^{I} x_{m t}\right)
$$

where $V^{I}$ is the conditional variance-covariance of asset payoffs.

$$
V^{I}=\operatorname{Var}\left[u_{t} \mid \theta_{1}\right]=\left[\begin{array}{ccc}
\sigma_{\epsilon}^{2} & 0 & 0 \\
0 & \sigma_{\eta}^{2}+\sigma_{\epsilon}^{2}-\frac{\sigma_{12}^{2}}{\sigma_{\eta}^{2}} & \sigma_{23}-\frac{\sigma_{12} \sigma_{13}}{\sigma_{\eta}^{2}} \\
0 & \sigma_{23}-\frac{\sigma_{12} \sigma_{13}}{\sigma_{\eta}^{2}} & \sigma_{\eta}^{2}+\sigma_{\epsilon}^{2}-\frac{\sigma_{13}^{2}}{\sigma_{\eta}^{2}}
\end{array}\right]
$$


The covariance between prices $P_{2}$ and $P_{3}$, is

$$
\operatorname{cov}\left(P_{2}, P_{3}\right)=\frac{1}{R^{2}}\left[\frac{\rho^{2}}{1-\rho^{2}} \sigma_{23}+\frac{\sigma_{12} \sigma_{13}}{\sigma_{\eta}^{2}}+a^{2} \sigma_{x}^{2} V_{23}^{I}\left(V_{22}^{I}+V_{33}^{I}\right)\right]
$$

The first term is the covariance between fundamentals, forecasted on the basis of last period's information. The second term is the covariance induced by forecasting the fundamentals of assets 2 and 3, using information about asset 1 . The higher the covariance of each asset with asset 1 , the stronger the inference made about the asset's value, and the more covariance generated by the inference problem. The final term arises because investors rebalance their portfolios to manage risk.

Proposition 1 Comovement Relative to Full Information: If $\sigma_{23}<\frac{\sigma_{12} \sigma_{13}}{\sigma_{\eta}^{2}}$, then the covariance of asset prices 2 and 3 is higher than it would be given full information: $\operatorname{cov}\left(P_{2}, P_{3}\right)>\operatorname{cov}\left(P_{2}^{F I}, P_{3}^{F I}\right)$

Proof: The result follows from equations (5) and (11).

The sufficient condition is that the correlation of innovations to the payoff process for assets $m$ and $n$ is less than the product of each asset's correlation with the information. If an investor observes a $\theta_{1}$ that is $\eta_{1}$ units higher than he expected it to be, then he will revise his beliefs about $\theta_{2}$ and $\theta_{3}$ upward by $\frac{\sigma_{12}}{\sigma_{\eta}^{2}}$ and $\frac{\sigma_{13}}{\sigma_{\eta}^{2}}$, respectively. The covariance between $\frac{\sigma_{12}}{\sigma_{\eta}^{2}}$ and $\frac{\sigma_{13}}{\sigma_{\eta}^{2}}$ is the right side of the inequality. If making inferences based on observations of signal one generates more covariance than the covariance between fundamentals $\left(\sigma_{23}\right)$, then excess price covariance results. The left panel of figure 1 shows the region of parameter values that generate excess covariance.

The requirement that payoff covariance between assets be small fits with the empirical excess correlation literature which focuses on price covariance between assets that appear unrelated. Pindyck and Rotemberg's (1993) original comovement test works with groups of assets whose earnings, after removing aggregate macroeconomic factors, have statistically insignificant correlation. It is exactly between these kinds of assets where payoff correlation is very low that the excess correlation generated by common information has the largest effect. 
This condition also makes sense from the perspective of an information purchaser. The asset that you would most want to have information on is the asset with the highest correlations with the other assets. This signal will have the greatest predictive power. If information purchase was endogenous and signal 1 was chosen, we would expect $\sigma_{12}$ and $\sigma_{13}$ to be high relative to $\sigma_{23}$.
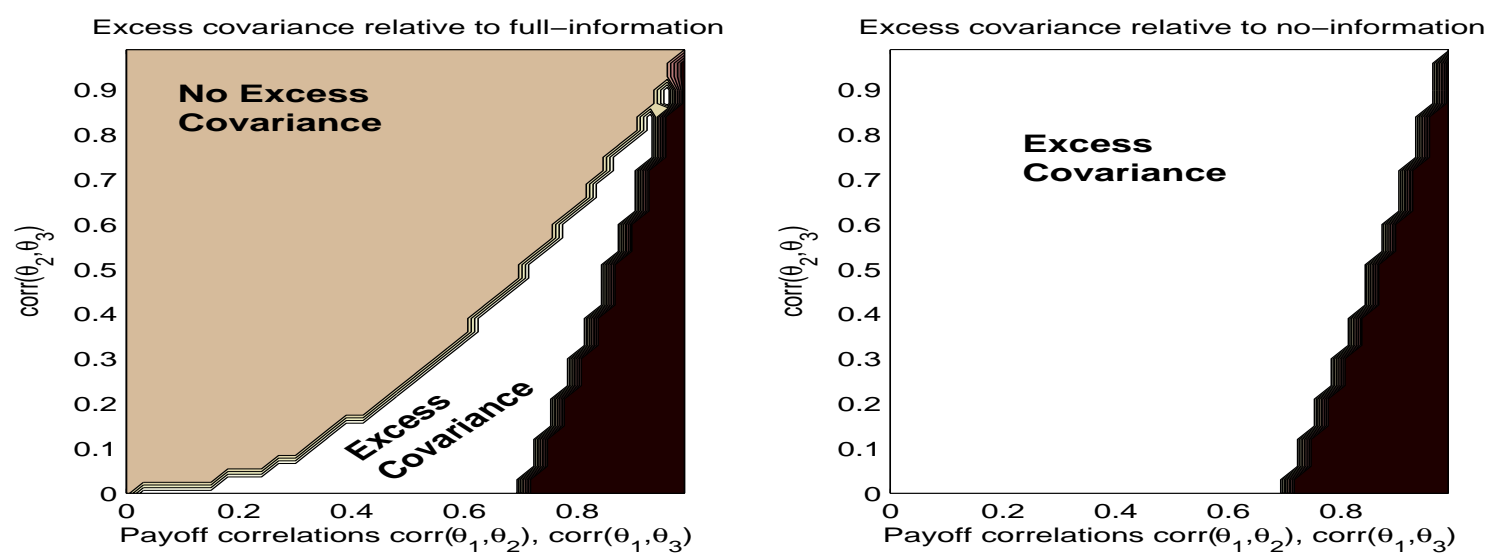

Figure 1: Regions of covariance parameters that generate excess price covariance between assets 2 and 3 relative to a full-information and a no-information benchmark. Axis labels are correlations $\left(\sigma_{m n} / \sigma_{\eta}^{2}\right)$. Black region covers inadmissable parameters that produce non-positive variance-covariance matrices. Parameters: $R=1.02, \mu=1, \rho=0.86, \sigma_{\eta}^{2}=0.1^{2}, \bar{x}=1, v x=0.5, \sigma_{\epsilon}=0.13^{2}, a=1.5$.

If the point of comparison is instead a no-information price, where agents only observe past states and prices, then the conditions for excess price covariance change. When noinformation payoff variance $\left(\sigma_{\eta}^{2}+\sigma_{\epsilon}^{2}\right)$ is not too large, price covariance between assets 2 and 3 is small.

\section{Proposition 2 Comovement Relative to No Information: If}

$$
\sigma_{23}<\frac{\sigma_{12} \sigma_{13}}{\sigma_{12}^{2}+\sigma_{13}^{2}}\left(1+a^{2} \sigma_{x}^{2}\left(\sigma_{\eta}^{2}+2\left(\sigma_{\eta}^{2}+\sigma_{\epsilon}^{2}\right)-\frac{1}{\sigma_{\eta}^{2}}\left(\sigma_{12}^{2}+\sigma_{13}^{2}\right)\right)\right)
$$

then the covariance of asset prices 2 and 3 is higher than it would be given no information: $\operatorname{cov}\left(P_{2}, P_{3}\right)>\operatorname{cov}\left(P_{2}^{N I}, P_{3}^{N I}\right)$

Proof: The result follows from comparing equations (7) and (11).

When agents learn about all assets, then the only risk comes from transitory $\epsilon$ shocks, which are independent across assets. When agents learn about only one asset, payoff risk is 
comprised partly of correlated shocks to $\theta$. When risk across assets is correlated, investors adjust portfolios to reduce covariance (diversify) and minimize risk. These portfolio adjustments dampen price covariance. The right panel of figure 1 shows the results of the numerical example: any admissible set of covariances generates excess price covariance, relative to a no-information benchmark.

\subsection{Introducing Asymmetric Information}

Next, consider the case where $\theta_{1}$ is observed by a fraction $\lambda$ of the investors. As before, no investors see $\theta_{2}$ or $\theta_{3}$. As soon as investors have different information sets, some will look to the price level as a signal of the information observed by others. Since the observed value of $\theta_{1}$ will affect informed traders' demand for all three assets, all three asset prices are informative signals for the uninformed. This section describes how uninformed agents solve their signal extraction problem and how the degree of asymmetry changes the extent of comovement.

There are two problems that must be solved simultaneously. The first question is: how do prices depend on fundamentals $\theta_{t}$ and $x_{t}$ ? The second problem is to discover what the optimal set of beliefs are for each type of agent, upon observing the price vector $P_{t}$.

The solution involves first postulating a linear rule for risky asset prices ${ }^{5}$

$$
P_{t}=A_{t}+B_{t} \eta_{t}+C_{t}\left(x_{t}-\bar{x}\right)
$$

where $\eta_{t}$ is a vector of innovations to the persistent component of payoff $\theta_{t}$ and $\left(x_{t}-\bar{x}\right)$ is a vector of unexpected asset supply shocks. Given this linear price rule, each agent solves a Kalman filtering problem to obtain expectations $E\left[\theta_{t} \mid \mathcal{F}_{i t}, P_{t}\right]$, as well as the variance of that expectation. While the price rule comprises the observation equation and is common to all agents, the state equation depends on the agent's information set $\mathcal{F}_{i t}$

$$
\eta_{t}=E\left[\eta_{t} \mid \mathcal{F}_{i t}\right]+\operatorname{Var}\left[\eta_{t} \mid \mathcal{F}_{i t}\right]^{1 / 2} \nu_{t}
$$

\footnotetext{
${ }^{5}$ This solution method is similar to that used by Admati (1985). However, this problem is distinct because Admati's agents all received different signals with identical variance. Here, the variance of agents' prior beliefs differs depending on whether they are informed or not.
} 
where $\nu_{t} \sim N(0,1)$.

To solve for the coefficients $A_{t}, B_{t}$, and $C_{t}$, and verify that price is linear, use the asset market clearing condition. Each agent's asset demand depends on their conditional expectation and variance of the assets' payoffs, as well as on the price $D_{i t}=\left(\operatorname{arar}\left[u_{t} \mid \mathcal{F}_{i t}\right]\right)^{-1}\left(E\left[u_{t} \mid \mathcal{F}_{i t}\right]-\right.$ $r P)$. Setting the weighted sum of all asset demands equal to the total asset supply yields the equilibrium price equation

$$
P=\frac{1}{R} V_{\lambda}\left(\sum_{i} \lambda_{i} \operatorname{Var}\left[u_{t} \mid \mathcal{F}_{i t}, P_{t}\right]^{-1} E\left[u_{t} \mid \mathcal{F}_{i t}, P_{t}\right]^{-1}-a x_{t}\right)
$$

where $V_{\lambda}=\left(\sum_{i} \lambda_{i} \operatorname{Var}\left[u_{t} \mid \mathcal{F}_{i t}, P_{t}\right]^{-1}\right)^{-1}$ and $i$ indexes the information portfolio. This pricing equation can be rewritten as a linear function of $\eta_{t}$ and $\left(x_{t}-\bar{x}\right)$. Matching coefficients yields implicit solutions for $A_{t}, B_{t}$ and $C_{t}$. where $\mathrm{B}$ and $\mathrm{C}$ solve

$$
\begin{aligned}
& B=\left[\lambda V_{I}^{-1} R+(1-\lambda) V_{U}^{-1}\left(R-K_{t}\right)\right]^{-1} \lambda V_{I}^{-1} B \\
& C=\frac{-a \sigma_{x}^{2}}{R}\left[\lambda V_{I}^{-1} R+(1-\lambda) V_{U}^{-1}\left(R-K_{t}\right)\right]^{-1} .
\end{aligned}
$$

The term $K_{t}$ is the Kalman gain: $K_{t}=\Sigma B^{\prime}\left(B \Sigma B+\sigma_{x}^{2} C C^{\prime}\right)^{-1}$. The variance of asset payoffs $\left(u_{t}\right)$, conditional on observed prices, for the uninformed agent is $V_{U}=\Sigma-K_{t} B \Sigma+\sigma_{\epsilon}^{2} I$. Finally, $A_{t}$ is the expected value of the price. ${ }^{6}$

Given this solution method for asset prices, we can now ask how the prices change when the amount of information $\lambda_{1}$ varies. Assuming that no agents are informed about assets 2 and 3, increasing the number of agents that observe information about asset 1 will increase price covariance. The reason is that the excess covariance is generated by people observing information about asset 1 and making correlated inferences about assets 2 and 3 . The more people who observe the information and the more precise the information they observe, the stronger the inferences they will make.

Proposition 3 Informing more agents increases comovement. If (12) holds, then

\footnotetext{
${ }^{6}$ The coefficients $B_{t}$ and $C_{t}$ cannot be solved for explicitly. However, a numerical algorithm that begins with a guess for $\mathrm{B}$ and $\mathrm{C}$ and then iterates on equations 14 and 15 until convergence, will produce a solution.
} 
there exists a non-empty set $\Lambda$ inside $[0,1]$ such that for $\lambda_{2}=\lambda_{3}=0$ and all $\lambda_{1} \epsilon \Lambda$, $\operatorname{cov}\left(P_{2}, P_{3}\right)$ is increasing in $\lambda_{1}$.

Proofs of this and all further propositions are in the appendix.
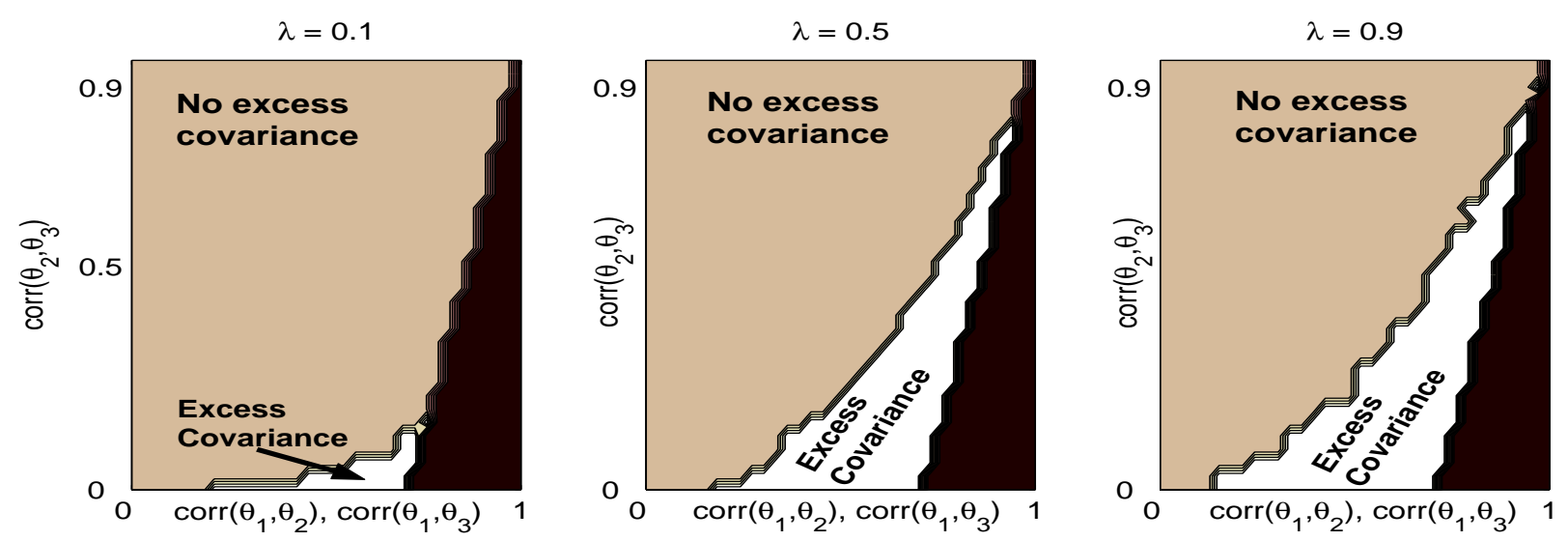

Figure 2: Regions of excess covariance, relative to full-information prices, for three values of $\lambda$, the fraction of the population that is informed. Increasing the number of informed agents increases the range of parameters that generate excess covariance. Axis labels are correlations $\left(\sigma_{m n} / \sigma_{\eta}^{2}\right)$. Black region covers inadmissable parameters that produce non-positive variance-covariance matrices. Parameters: $R=1.02, \mu=1, \rho=0.86$, $\bar{x}=1, v x=0.5, a=1.5, \sigma_{\eta}^{2}=0.1^{2}, \sigma_{\epsilon}^{2}=0.13^{2}$.

Figure 2 shows a numerical example where, as the fraction of the population that observes $\theta_{1}$ rises, so does the excess covariance of prices 2 and 3. As more people become informed, the asset prices reveal more information, and investors make stronger inferences about the appropriate prices of assets 2 and 3 , based on the signal $\theta_{1}$.

\subsection{Properties of the Information Market}

Two properties of information markets are critical in generating comovement: Investors buy common signals, and the signal that they buy are the ones that can generate the largest excess covariance. The common signals result from price complementarity in information markets. The signals chosen are not a result of the information market structure, but follow from the desire to minimize payoff variance.

Result 1 In equilibrium, information suppliers will price all information at its average cost. 
Free entry at the stage where prices are set ensures that all profits are competed away; zero profit implies average cost pricing. The fact that the price of information declines in the quantity of people who buy it is critical because it creates a complementarity: Investors want to buy the same information because that information is cheap. It is this information complementarity that will cause investors in the multiple signal model to hold largely identical information portfolios and pass on common shocks to many asset prices.

Taking the price of information as given, how to agents choose information demand? Since all agents are identical ex-ante, $\lambda_{i} \epsilon(0,1)$ is an equilibrium when all agents are indifferent between buying signal $i$ or not: $E\left[u\left(W_{t+1}^{I}\right)\right]=E\left[u\left(W_{t+1}^{U}\right)\right]$ where $W^{I}$ and $W^{U}$ denote the wealth of informed and uninformed agents.

What is the optimal order in which signals are provided? The highest-value signals are the ones that reduce the variance of total payoffs by the largest amount. Suppose an investor holds a portfolio with a vector of weights $\alpha$ on each asset. Then, if $V$ is the variancecovariance matrix of payoffs, the variance of the portfolio will be $\alpha^{\prime} V \alpha$. The question is, how much does each signal reduce this variance? Signal $i$ reduces the portfolio variance by

$$
\alpha^{\prime}\left(\Sigma-V^{I}\right) \alpha=\alpha_{i}\left(\alpha_{i} \sigma_{\eta}^{2}+2 \alpha_{j} \sigma_{i j}+2 \alpha_{k} \sigma_{i k}\right)+\alpha_{j}^{2} \frac{\sigma_{i j}^{2}}{\sigma_{\eta}^{2}}+2 \alpha_{j} \alpha_{k} \frac{\sigma_{i j} \sigma_{i k}}{\sigma_{\eta}^{2}}+\alpha_{k}^{2} \frac{\sigma_{i k}^{2}}{\sigma_{\eta}^{2}}
$$

The three terms in parentheses describe how removing $\theta_{i}$ as a risk factor directly decreases variance. The second three terms describe how observing $\theta_{i}$ allows investors to make better predictions about $\theta_{j}$ and $\theta_{k}$ and reduce variance indirectly.

This result tells us that two properties of a signal make it useful in reducing variance. The first property is that you expect to hold lots of the signal (high $\alpha_{i}$ ). Ex-ante, all agents are identical. Each must hold 1/3rd of the stock of each asset. So, ex-ante differences in $\alpha$ 's are not explaining information demand. The second property is that the signal has high covariance with the other signals $\left(\sigma_{i j}, \sigma_{i k}\right.$ large). The signal chosen therefore is the one with the strongest power to predict other signals. Proposition 2.1 tells us that excess covariance arises when $\frac{\sigma_{i j} \sigma_{i k}}{\sigma_{\eta}^{2}}$ is larger than $\sigma_{j k}$. So, this signal with the highest covariances with the other two signals is the signal most capable of generating excess covariance and the first signal that information markets will supply. 


\subsection{The Full Model with Multiple Signals}

There are two properties of the multiple-signal model of particular interest. First, how does observing multiple signals affect excess covariance? Second, what do the optimal information portfolios looks like, and how do they differ from fixed-information-cost portfolios? Section 2.2 demonstrated that as the information market deepens, and demand for one signal rises, comovement increases. In contrast, as information demand broadens and more signals are purchased, comovement declines. With fixed-cost information, signals that other agents don't observe are more valuable. Therefore, information demand is broad and comovement is low. With endogenous-cost information markets, investors will buy high demand information, even though it is less valuable, because it is cheap. Information demand will be deep and comovement high.

As the variety of signals purchased rises, asset prices approach their full-information levels and excess covariance disappears.

Proposition 4 Comovement Falls When More Signals Are Observed. If $\lambda_{1}=1$, $\lambda_{3}=0$, and $\sigma_{23}<\frac{\sigma_{12} \sigma_{13}}{\sigma_{\eta}^{2}}$, then $\operatorname{cov}\left(P_{2}, P_{3}\right)$ is decreasing in $\lambda_{2}$ over some non-empty interval $\Lambda \subset(0,1)$.

If information becomes more abundant, there are two competing effects. More people becoming informed about one asset increases excess covariance. But, if information demand starts spilling over into other assets, price covariance falls. Price covariance can arise where there are two assets whose values are not directly observed by some agents, but are being inferred on the basis of some common information. In the simple case where there are three assets, this means that comovement arises primarily when only one asset is being learned about. When investors start learning about two assets, only one price is being determined based on inference, and comovement cannot arise. As the number of assets (N) grows, comovement will still be strongest when most agents observe one signal. In that case there are $(N-1)$ assets all being priced based on the same signal. As more signals are observed, fewer assets are susceptible to comovement, and the ones that are will be priced based on more nuanced, and less common information. The comovement effect will diminish and eventually disappear when $(N-2)$ signals are observed. In short, excess price covariance arose because 
of an incomplete information problem. When information becomes more complete, the effect disappears.

Proposition 4 also highlights the importance of information markets in the model. If agents purchased many different signals in equilibrium, price covariance would be similar to that in a full-information model. Price would just have some extra idiosyncratic noise.

Unfortunately, information demands cannot be neatly characterized in analytical form. The solution relies on the extent to which investors can learn from the price level, which in turn depends on the price rule. However, the expressions for the price rule in equations (14) and (15) can be solved numerically in seconds, but cannot be used to analytically express the equilibrium information demand. The reason for the complexity lies in information decision problem: a seven-dimensional optimization problem with both strategic complementarity and substitutability. The problem is distinct from the one-asset solution method employed in Grossman and Stiglitz (1980). Models where information is exogenous (e.g. Kodres and Pritsker 2001, and Admati 1985) also do not run into these technical dilemmas. To understand the nature of the information portfolios, we'll have to turn to numerical simulation results.

\subsection{Calibration and Simulation}

Numerical examples will illustrate the interesting features of the model's information portfolios. To make these numerical results realistic, model parameters are matched to asset pricing moments from the S\&P 500. The payoff autocorrelation parameter $\rho$ is 0.86 , matching the price autocorrelation. ${ }^{7}$ The variance of the persistent payoff innovation $\sigma_{\eta}$ determines both the Sharpe ratio and the equity premium. This model, like most, cannot match both statistics. The benchmark value is $\sigma_{\eta}^{2}=0.1^{2}$, an intermediate value that generates a Sharpe ratio of 2.6 and an equity premium of $3 \%$. Section 3.1 explores a range of values between $0.025^{2}$ and $0.2^{2}$. The transitory payoff shock $\epsilon$ makes payoffs more volatile, but is never learned and therefore never incorporated into prices. Therefore, a natural moment to match $\sigma_{\epsilon}^{2}$ to is the ratio of return variance to price variance (0.62 in the data); this yields $\sigma_{\epsilon}^{2}=0.13^{2}$.

\footnotetext{
${ }^{7}$ Since a positive trend in prices will inflate their correlation as well as their variance, I first detrend prices using a loglinear trend. The data is yearly returns and average price levels from 1946-2003.
} 
The variance of the asset supply shock $\sigma_{x}^{2}$, together with the cost of information, determines how much information will be held in equilibrium. For excess covariance to have a fighting chance in a three-asset model, most agents must purchase one signal in equilibrium. Therefore $\left(\sigma_{x}^{2}=0.5\right)$ and $\chi=0.1$ were chosen so that the average number of signals purchased is 0.95. The real return on a risk-free asset is $2 \%$. Absolute risk aversion $a$ is 1.5 , producing an average relative risk aversion of 4.5. The mean asset payoff and average number of shares per capita do not affect second moments. They are both set to 1 .

The last question is: What should the correlation structure of the three assets be? There are no population moments, only specific examples. Payoff correlations are matched to the correlation of dividends of three S\&P500 firms. The firms, Nordstrom (retail), PitneyBowes (business services) and Sysco (food services), exhibit the pattern of excess covariance predicted by my model: Pitney and Sysco both have high correlation with Nordstrom (0.705 and 0.500$)$, a low dividend correlation with each other $(0.201)$, and a price covariance much higher than would be predicted by their fundamentals (0.524). Based on this example, the model's asset payoffs have correlations of $0.7,0.5$ and 0.2 .

Optimal information portfolios are selected by simulating a 20-agent market and asking what expected utility an agent would have achieved with each signal combination. An equilibrium is a set of information portfolios such that no agent would achieve a higher utility with any other signal, given the signals other agents are holding. The search algorithm begins with initial information portfolios and then lets agents optimize sequentially, holding other agents' information fixed, until no agent wants to change his portfolio.

\subsection{Numerical Results: Information Portfolios and Comovement}

Three interesting features of optimal information portfolios stand out: information demand is clustered; the optimal signals maximize comovement, and information demand can shift suddenly. To examine each feature, let's look at a sequence of optimal information portfolios as the variance of payoffs $\sigma_{\eta}^{2}$ is increased. Recall that as $\sigma_{\eta}^{2}$ rises, so does the value of information. In the top panel of figure 3, a vertical slice of the graph depicts an equilibrium information portfolio for a given payoff variance. 

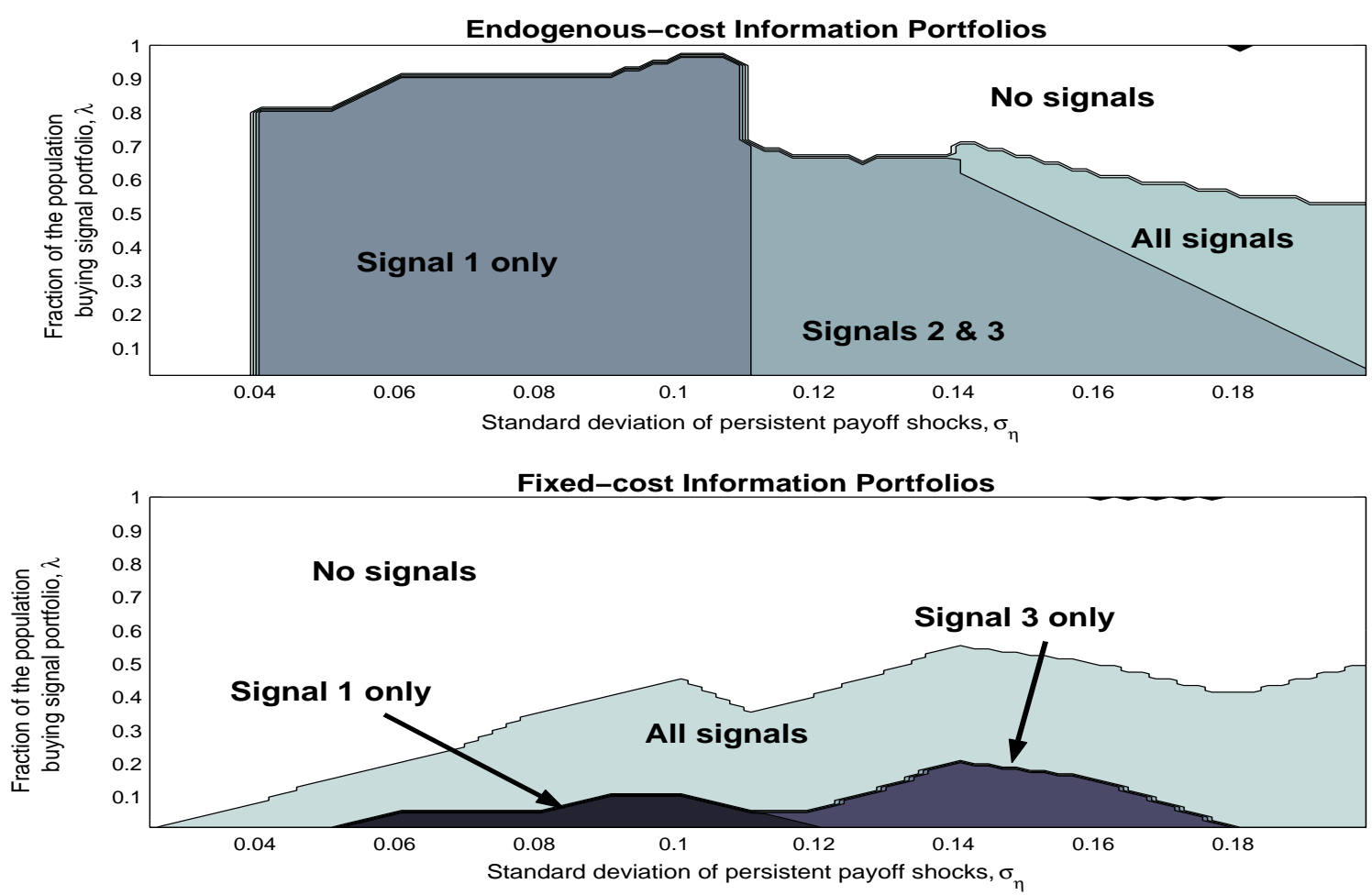

Figure 3: Distribution of information portfolios over the population, for varying levels of asset payoff risk. For a given variance parameter, a vertical slice of this graph tells you what fraction of the population buys each signal. With information markets, demand is concentrated on a smaller set of signals.

When variance is very low and uncertainty is low, agents buy no signals. When they do start to buy signals, a large fraction of the population all buy the same signal. This is the clustering of information demand, concentrated on a small number of signals, that ensures that the same shocks to signals get passed on to prices of all three assets. As variance rises, agents switch from buying signal 1 to buying signals 2 and 3, to eventually buying all 3 signals. The reason for this pattern is that asset 1 has the highest correlation with the other two assets. If you want to predict the payoffs of all three assets based on one signal, signal 1 has the strongest predictive power. When buying two signals, signals 2 and 3 are optimal because they are both good at predicting the payoff of asset 1. More generally, when information is not very valuable, it is optimal to purchase a few signals that are highly correlated with many assets. When information demand rises, a more diversified information portfolio that focuses on hard-to-predict assets yields higher payoffs.

The shift between a market focus on a few important summary statistics and a more 
nuanced approach to evaluating many individual assets can happen quite suddenly. The sudden switch is because of the endogenous information price. If the price per signal was constant, regardless of how many people bought it, then information demand would be a continuous function that gradually declined as $\sigma_{\eta}^{2}$ fell. With an endogenous information price, few people purchasing $\theta_{1}$ makes the signal very expensive. When an increase in the variance makes information more valuable and demand rises, the price of information falls. This causes a discrete shift to a regime where many investors buy the signal and this is optimal because the signal is very cheap.

The effect of discrete information shifts will resemble the paradigm shift of Hong and Stein (2003). In that setting, investors switch focus from one set of indicators to another because they are changing the model they use to forecast. Here, shifts come from changes in the information sets agents choose to acquire. The shifts in themselves are interesting because they could be triggered by small events and would have large consequences for the cross-section of asset prices.

Contrast the portfolios purchased from information markets with the bottom panel of figure 3, where the cost of information is fixed. ${ }^{8}$ The average number of signals per person is not very different in the two models. But, instead of having many agents concentrate their demand on a small number of signals, there are fewer agents buying many signals. Agents diversify their information portfolios when information costs are fixed because information that is not already held and not already reflected in the price is more valuable. Recall that excess covariance is strongest when a large fraction of agents hold the same small subset of signals. Thus, diversity of information in the fixed-cost model dampens the common shocks to prices and washes away most excess price covariance.

How much comovement can these information portfolios generate? When the payoff variance is $\sigma_{\eta}^{2}=0.1^{2}$, as in the calibrated model, then $95 \%$ of agents purchase signal 1 and excess covariance is 0.0015. Since covariance arises partly because the variance of price changes, it is useful to isolate comovement by looking at correlations. The correlation between the prices of assets 2 and 3 is $43 \%$ higher than it would be if agents had a full set of signals, and

\footnotetext{
${ }^{8}$ The price of a signal in the fixed-information-cost model is equal to the average signal price paid in the endogenous cost model: $\chi / 0.8$.
} 
is $108 \%$ higher than the correlation in the asset payoffs. Comovement is present, even when there is full information, because agents rebalance the risk in their portfolios in response to news, affecting their demand for unrelated assets. However, this effect is tiny.

With the fixed information cost portfolio, comovement still appears, but is only $7.1 \%$ higher than for the full-information price. The reason correlation is so low is that when different agents hold different information portfolios, they make different prediction errors about asset values that cancel each other out in the market price. Only when many agents are making the same inference errors will comovement be strong.

The extent of the correlation in the asset price still does not match the correlation in the prices of Sysco and Pitney, in the data example (excess of $108 \%$ in the model vs. 161\% in the data). However, some of that price covariance could be explained by forces absent in this model, such as macroeconomic fluctuations that affect the stochastic discount factor used to price all assets.

Does this excess covariance show up in returns as well? Yes, it does. The return is the asset payoff divided by its price $\left(\frac{u_{m t}}{P_{m t}}\right)$. For the information markets model, the correlation between the returns on assets 2 and 3 is $28 \%$, while for the fixed-cost information and full information models, the correlation is almost zero $(<0.3 \%)$.

In a model with only 3 assets, the region that generates excess covariance appears to be quite limited. However, in a richer model with $N$ assets, excess covariance will be possible whenever agents are purchasing between 1 and $N-2$ of the signals. (See section 2.4.) With more assets, the range of parameters that generates excess covariance will grow.

\section{Related Issues}

\subsection{Business Cycle Variation in Comovement}

Patterns of comovement change over the business cycle. In particular, comovement is higher in recessions than in booms (Ribeiro and Veronesi 2002, Zuckerman and Rao 2003). Can the model match this fact?

As the model is formulated right now, there is no force causing information demand to 
fluctuate. This is because the variance of payoff innovations $\sigma_{\eta}^{2}$ was held fixed, for simplicity. For information provision to vary systematically over the business cycle, the level and variance of asset payoffs $\left(\theta_{t}\right)$ need to be tied together. The most natural way to think of the effect of increasing the payoff level is to think of issuing more shares of the asset. If you hold a given fraction of the assets and the number of shares rises, the mean and standard deviation of the payoffs rise proportionately. If you scale the standard deviation of payoff innovations up and down with the existing payoff level $\hat{\theta}_{t-1}$ each period, the resulting payoff process is

$$
\theta_{m t}=(1-\rho) \mu_{m}+\rho \theta_{m(t-1)}+\theta_{m(t-1)} \eta_{m t} .
$$

Risk, the ratio of the standard deviation of future payoffs to the current payoff, stays constant, while the total variance $\left(\theta_{t}^{2} \sigma_{\eta}^{2}\right)$ of the payoff fluctuates.

If total variance rises, information becomes more valuable and therefore more abundant. Why does total variance determine information demand? Total variance is the product of risk and the asset value. Risk matters because information on a very stable payoff process is not nearly as useful as information on a payoff that varies greatly. The asset value matters because it determines how much is at risk. Information here has increasing returns. You can use one piece of information to evaluate a little bit of an asset or you can use the same signal to value a large amount of asset value. You get more mileage out of information that is used to evaluate a higher value asset. The same effect was present when we examined what signals most reduced variance (equation 16). Holding more shares of an asset made learning about that asset more valuable. Likewise, holding more value in an asset also makes information about that asset more valuable.

Increasing information provision when asset values are high has two competing effects on comovement. One effect is to make more people learn about the same subset of assets. If the fraction of informed people rises, existing comovement will be made stronger (proposition 2.2). The other effect is to make information available about a broader class of assets. This would reduce the extent to which investors use information about one asset to make inference about others and reduce the extent of comovement (proposition 4). If broadening the information set is a stronger force than enlarging the size of the informed population, then 
as payoffs and risk rise, comovement will fall; prices will exhibit countercyclical comovement.

From figure 3, it is clear that more variance has a weak effect on the number of informed agents and a much stronger effect on the number of signals purchased. It is the region where many agents purchase signal 1 and almost no agents purchase other signals ( $\sigma_{\eta}$ between 0.04 and 0.11), where excess covariance between the prices of assets 2 and 3 will arise. When payoff variance is very low and no signals are purchased, prices will be based only on past observations; this will not generate any excess covariance. Likewise, when payoff variance is high and all agents are buying two or three signals, there are not two assets whose prices are determined by inference. Only in the intermediate range, where most agents are buying one signal, can the covariance between two prices exceed the full-information covariance. Therefore, if the mean value of $\sigma_{\eta}$ is 0.1 , comovement is more likely when asset prices are below average, than when they are above average. This is the source of the model's countercyclical comovement.

How much more comovement is generated in bad times than in good times? Figure 4 shows how the correlation between the prices of assets 2 and 3 changes as the expected asset payoff $\left(\hat{\theta}_{t}\right)$ grows. I use correlations here instead of covariances because the entire environment is becoming more volatile as $\sigma_{\eta}$ grows. The correlation is high in the region where many agents are purchasing signal 1 and low in the regions where information is very scarce, or where multiple signals are abundant. The mean of the asset payoff is 1 . Therefore, when times are bad and asset payoffs are low, excess correlation (the difference between information market and full-information covariance) is high.

Of course, choosing a different mean for $\sigma_{\eta}$ could easily produce the opposite conclusion, that comovement increases in good times. However, if you extend this logic to a larger class of assets, comovement will be strongest when all investors use only one signal to price all assets. As the number of signals rises, and investors construct more accurate forecasts of payoffs, comovement falls. It is only the case where people switch from seeing no signals to seeing one signal that comovement increases with the information supplied. Certainly in the U.S., the idea that many people stop learning anything about equity markets in downturns seems implausible. If people buy fewer signals in downturns, but still buy at least one signal, then downturns should be times of high comovement. 


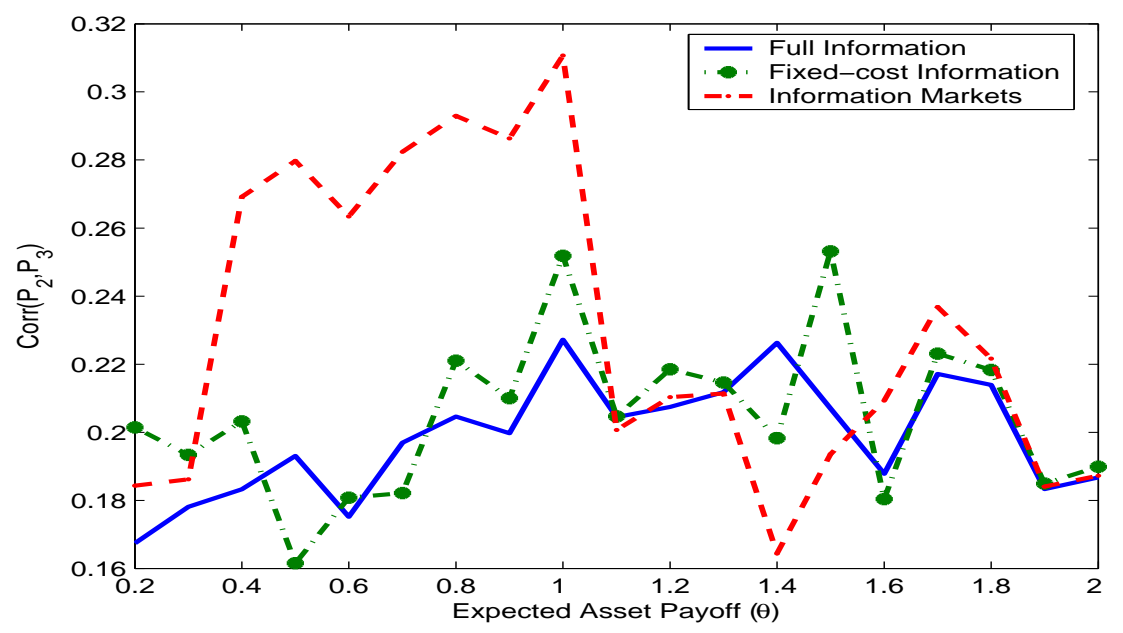

Figure 4: Asset price correlations for full-information, fixed-cost information, and market for information models. Excess correlation is the distance between the dotted and starred lines with the solid line. Information markets make excess correlation rise and then fall with asset payoffs.

\subsection{Twin Stocks}

Sometimes the same asset trades on two different markets. The price of the same asset on each market comoves more with its own market than with its twin asset (Froot and Dabora 1999). Hardouvelis, La Porta and Wizman (1994) document the same pattern of closed-end country funds having higher covariance with the market they are traded in than with the market where their underlying assets are traded. This theory says that the other assets in traders' portfolios should affect the price of a single asset. The reason is that these other assets determine what set of information traders purchase. An asset that is traded by people who learn lots of information about US stocks will have more covariance with US stocks and an asset traded by people who learn primarily about UK stocks will have more covariance with UK assets.

If you took an asset in this model and put it in a market with two other assets that you call US assets, and then you took the same asset with the same sequence of payoff shocks and put it in a market with two different assets that you call UK assets, the covariance of the asset in each setting changes substantially. Call the twin asset listed on both markets $T$ with prices $P_{T}^{U S}$ and $P_{T}^{U K}$. It is a claim to the same payoff in every period and is subject to identical asset supply shocks in both markets. In each market, there are two additional 
assets, which are not common. In the US, there are assets $S 1$ and $S 2$ with prices $P_{S 1}$ and $P_{S 2}$. In the $\mathrm{UK}$, there are assets $K 1$ and $K 2$ with prices $P_{K 1}$ and $P_{K 2}$. Investors in each market hold only the assets in their market. Half of these investors buy information about either $S 1$ or $K 1$.

\begin{tabular}{||l|c|c||}
\hline & $P_{T}^{U S}$ & $P_{T}^{U K}$ \\
\hline Correlation with $\left(P_{S 1}+P_{S 2}\right)$ & 0.70 & 0.60 \\
\hline Correlation with $\left(P_{K 1}+P_{K 2}\right)$ & 0.90 & 0.73 \\
\hline
\end{tabular}

Table 1: Simulated asset markets (US and UK) that have one asset $T$ in common. The payoffs and asset supply shocks for $T$ are identical in both markets. Asset payoff covariances are: $\sigma_{T, K 1}=.8, \sigma_{T, K 2}=.8, \sigma_{K 1, K 2}=.5, \sigma_{T, S 1}=.65, \sigma_{T, S 2}=.65, \sigma_{S 1, S 2}=.5 . \quad \lambda=0.5 .10,000$ iterations.

Since the shares of $T$ traded in each market are identical assets, we would expect for them to have the same correlations with each market. This result underlines the main point that asset prices can be influenced by the prices of other assets being traded in the same market, when information about assets is incomplete.

\subsection{Decreasing Covmovement over Time}

Asset price comovement has been steadily decreasing in the U.S and emerging markets (Morck, Yeung, Yu 2000). At the same time, information technology has made the collection and dissemination of information easier. According to the model, falling information costs can cause a more diverse set of signals to be supplied to investors. Instead of learning about one asset in an industry when information was very expensive, investors now have detailed firm-level information available at low cost. Proposition 4 says that more detailed information moves market prices closer to full-information pricing, which exhibits no excess covariance.

\section{Conclusion}

As the same piece of information is being simultaneously incorporated into many asset prices by a large number of investors, it causes the prices to move in a correlated way, even if 
the asset payoffs are uncorrelated. By supplying the highest-value information, information markets naturally supply signals that are relevant for many asset prices. By supplying signals at the lowest possible cost, information markets ensure that the same signals are provided to many investors.

When thinking about what information will be supplied by information markets, the analysis has focused on signals about asset payoffs. However, there is a whole spectrum of asset-payoff relevant information that could be rationally supplied and could produce comovement. For example, if a component of each asset's payoff was due to movements in the unemployment rate, then discovering and selling unemployment data might be an equilibrium outcome. Alternatively, many assets with uncorrelated payoffs could have correlated prices if investors observe a market index that is a weighted sum of the assets' payoffs. For comovement to arise, it is not so important what people learn about, as long as the information is relevant for valuing many assets. When information is costly, this is exactly the kind of high-value information that markets supply.

The analysis has focused on the simplest possible case, where there are three assets. This too can be relaxed. As long as there are two or more assets being priced by the same noisy signal, excess covariance can arise. With three assets, excess covariance disappears when two signals are observed, because there is only one asset left being priced with noisy information. If there were 100 assets, investors would have to purchase information about 99 of them before all excess covariance disappeared. However, solving a model with many assets, using the current method, is infeasible. Because the number of possible information portfolios is the number of combinations of signals, the complexity of finding the optimal portfolio grows exponentially.

The related phenomena of contagion, correlated outflows of foreign investment (Albuquerque, Bauer and Schneider 2003), and cross-country asset price correlation (Shiller 1989), could all be re-examined through the lens of information markets. Earlier research explains the cross-market comovement of asset prices and real flows using investors' portfolio rebalancing decisions, arising either from a wealth shock (Kyle and Xiong 2001) or correlations in fundamentals (Kodres and Pritsker 2002). These shocks can be magnified when there are uninformed investors who cannot distinguish noise trading or portfolio rebalancing effects 
from bad news about asset payoffs (King and Wadhwani 1990). By characterizing optimal information portfolios, this paper contributes to this line of research, explaining where and when information asymmetry is likely to arise. But it also shifts the focus of the inquiry from looking at properties of asset payoffs or noise trading, to the choice of information sets, used to form expectations of assets' values. 


\section{References}

[1] Admati, Anat. "A Noisy Rational Expectations Equilibrium for Multi-Asset Securities Markets." Econometrica, 1985, v.53(3), pp.629-57.

[2] Albuquerque, Rui; Gregory Bauer and Martin Schneider. "International Equity Flows and Returns: A Quantitative Equilibrium Approach." Working paper, 2003.

[3] Angeletos, George-Marios; Pavan, Alessandro. "Transparency of Information and Coordination in Economies with Investment Complementarities." American Economic Review forthcoming, 2004.

[4] Barberis, Nicholas; Andrei Shleifer and Jeffrey Wurgler. "Comovement." Journal of Financial Economics forthcoming, 2002.

[5] Calvo, Guillermo. "Contagion in Emerging Markets: When Wall Street is a Carrier." Working paper, 1999.

[6] Campbell, John; Martin Lettau, Burton Malkiel and Yexiao Xu. "Have Individual Stocks Become More Volatile? An Empirical Exploration of Idiosyncratic Risk." Journal of Finance, 2001, v.56, pp.1-43.

[7] Campbell, John; Lo, Andrew and MacKinlay, Craig. The Econometrics of Financial Markets. Princeton University Press, Princeton, NJ, 1997.

[8] Durnev, Art; Randall Morck and Bernard Yeung. "Value Enhancing Capital Budgeting and Firm-Specific Stock Return Variation." Journal of Finance, Forthcoming 2003.

[9] Grossman, Sanford and Stiglitz, Joeseph. "On the Impossibility of Informationally Efficient Markets." American Economic Review, 1980 , vol.70 (3), pp.393-408.

[10] Hong, Harrison and Stein, Jeremy. "Simple Forecasts and Paradigm Shifts." NBER working paper \#10013, 2003.

[11] King, Mervyn and Wadhwani, Sushil. "Transmission of Volatility between Stock Markets." Review of Financial Studies, 1990, v.3(1), pp.5-33.

[12] Kodres, Laura and Matthew Pritsker. "A Rational Expectations Model of Financial Contagion." Journal of Finance, 2002, vol.57(2), pp.769-799.

[13] Kyle, Albert and Wei Xiong. "Contagion as a Wealth Effect." Journal of Finance, 2001, vol.56(4), pp.1401-39.

[14] Lorenzoni, Guido. "Imperfect Information, Consumers' Expectations and Business Cycles" Princeton University, 2004.

[15] Morris, Stephen and Shin, Hyun Song. "Unique Equilibrium in a Model of Self-Fulfilling Currency Attacks." American Economic Review, v.88(3), 1998, pp.587-97. 
[16] Morck, Randall; Bernard Yeung and Wayne Yu. "The Information Content of Stock Markets: Why do Emerging Markets Have Synchronous Stock Price Movements?" Journal of Financial Economics v. 58, 2000, pp.215-260.

[17] Pindyck, Robert and Julio Rotemberg. "The Comovement of Stock Prices." Quarterly Journal of Economics November 1993 pp.1073-1104.

[18] Ribeiro, Ruy and Pietro Veronesi. "The Excess Comovement of International Stock Markets in Bad Times: A Rational Expectations Equilibrium Model." mimeo, University of Chicago GSB, 2002.

[19] Shiller, Robert. "Comovements in Stock Prices and Comovements in Dividends." Journal of Finance 1989, v.44(3), pp.719-29.

[20] Veldkamp, Laura. "Media Frenzies in Markets for Financial Information." NYU Stern working paper, 2004. pp. 695-732.

[21] Woodford, Michael. "Imperfect Common Knowledge and the Effects of Monetary Policy." in P. Aghion, R. Frydman, J. Stiglitz, and M. Woodford, eds., Knowledge, Information and Expectations in Modern Macroeconomics: In Honor of Edmund S. Phelps, Princeton, NJ: Princeton Univeristy Press, 2002.

[22] Zuckerman, Ezra and Rao, Hayagreeva. "Shrewd, Crude or Simply Deluded? Comovement and the Internet Stock Phenomenon." MIT Sloan working paper, 2003. 


\section{A Appendix}

\section{Proof of Proposition 3}

If (12) holds, then $\operatorname{cov}\left(P_{2}, P_{3}\right)$ is higher when $\lambda_{1}=1$ than when $\lambda_{1}=0$. Price covariance with $\lambda \epsilon(0,1)$ is

$$
E\left[P P^{\prime}\right]=B \Sigma B^{\prime}+\sigma_{x}^{2} C C^{\prime}
$$

Note that (14), (15) and (18) are all continuous functions of $\lambda$. The covariance of $P_{2}$ and $P_{3}$ is the $(2,3)$ entry of the $E\left[P P^{\prime}\right]$ matrix. If this covariance is higher at $\lambda=1$ than at $\lambda=0$ and varies continuously in $\lambda$ for all $\lambda \epsilon(0,1)$, then there must be some region $\Lambda \subset(0,1)$ where covariance in increasing in $\Lambda$.

\section{Proof of Proposition 4}

Proof: If $\lambda_{2}=1$, the price of asset 2 is the full-information price $P_{2}=\frac{1}{R}\left(\theta_{2}-a \sigma_{\epsilon}^{2} x_{2}\right)$. The price of asset 3 is $\frac{1}{R}\left(E\left[\theta_{3} \mid \theta_{1}, \theta_{2}\right]-a V_{3} x_{2}\right)$, where $V_{3}=\sigma_{\eta}^{2}-\Sigma(1: 2,3)^{\prime} \Sigma(1: 2,1: 2)^{-1} \Sigma(1: 2,3)$. The covariance between these two prices is

$$
\begin{aligned}
\operatorname{cov}\left(P_{2}, P_{3}\right) & =E\left[\eta_{2} E\left[\eta_{3} \mid \eta_{1}, \eta_{2}\right]\right]+\rho^{2} E\left[\theta_{2} \theta_{3}\right] \\
& =\sigma_{23}+\frac{\rho^{2}}{1-\rho^{2}} \sigma_{23}=\frac{1}{1-\rho^{2}} \sigma_{23}
\end{aligned}
$$

which is the same as the covariance between full-information prices. Proposition 2.1 shows that when $\sigma_{23}<\frac{\sigma_{12} \sigma_{13}}{\sigma_{\eta}^{2}}$, then the price covariance when $\left[\lambda_{1}, \lambda_{2}, \lambda_{3}\right]=[1,1,0]$. is less than when $\left[\lambda_{1}, \lambda_{2}, \lambda_{3}\right]=[1,0,0]$. Therefore, by continuity of price covariance in $\lambda$ (established proposition 2.2), there must be some non-empty region $\Lambda$ where $\operatorname{cov}\left(P_{2}, P_{3}\right)$ is decreasing in $\lambda_{2}$. 